\title{
Heat Exchange Evaluation at Thermo-Adhezion Method of Extraction of Diamond Raw from Kimberlite Ore
}

\author{
P. P. Sharin ${ }^{1}$, M. P. Lebedev ${ }^{1}$, G. M. Nikitin², G. G. Vinokurov ${ }^{1} \&$ M. P. Akimova ${ }^{1}$ \\ ${ }^{1}$ Insitute of physical technical problems of the North named after V.P. Larionov of Siberian Branch of Russian \\ Academy of Sciences, 677980, Russia \\ ${ }^{2}$ Institute "Yakutniproalmaz", 678174, Republic of Sakha (Yakutia) \\ Correspondence: G. G. Vinokurov, Insitute of physical technical problems of the North named after V.P. Larionov of \\ Siberian Branch of Russian Academy of Sciences, 677980, Russia. E-mail: g_g_vinokurov@iptpn.ysn.ru
}

Received: December 20, 2017

Accepted: December 28, 2017

Online Published: February 27, 2018

doi:10.5539/mer.v8n1p23

URL: https://doi.org/10.5539/mer.v8n1p23

\begin{abstract}
In the work thermo-adhesion a method of selecting and extracting the grains of diamond from a mixture of related minerals is developed. The study presents estimates of the heat transfer of the proposed scheme extraction based on the difference between the thermal conductivity of diamond and related minerals. The high selectivity thermo-adhesion selection and extraction of diamonds with the division concentrate on useful component and waste rock is shown.
\end{abstract}

Keywords: device, diamond, enrichment, heat conductivity, kimberlite, related minerals, rosin, thermo-adhesion substance

\section{Introduction}

At present, the extraction of raw diamonds is one of the highly profitable and promising sectors of the mining industry (Milashev, 2013; Shirey et al., 2002; Banas, Stachel, Muehlenbachs, \& McCandless, 2007; Tappert \& Tappert, 2011; Howell, 2012). Kimberlite or placer deposits are subjected to treatment by various methods to extract diamonds; removal of rock and other minerals occurs during enriching, and as a result, there a concentrate remains from which diamonds are extracted. Physical, chemical and magnetic properties of diamonds, the characteristics of related minerals and rocks are used in the extraction of diamonds from rock (Mukhin, Riu, \& Francheskini, 2015; Chaikovskii et al., 2013; Pastewka, Moser, Gumbsch, \& Moseler, 2011; Maréchal et al., 2014).

Thus, enrichment is the most knowledge-intensive stage of the technological process of diamond mining. At the final stage of enrichment after the X-ray-luminescent separation of diamond raw materials, a manual selection of diamond grains takes place, which is characterized by low productivity. To increase the efficiency of this technological operation, mechanization of manual labor, based on the automatic extraction of diamond grains, is required.

As it is known, one of the unique properties of diamond is a very high thermal conductivity among all solids, including all metals, natural minerals and rocks (Monticone et al., 2013; Dement'ev, Voiloshnikov, \& Kononko, 2015; Makarskii, 2012; Fedorov, Chepurov, \& Dereppe, 2002; Chanturiia et al., 2012). An analysis of thermal physical properties shows that, in comparison with diamond grains, kimberlite, rocks and related minerals from deposits are characterized by a much lower level of thermal conductivity - by $\sim 2-3$ orders of magnitude.

Thus, the technology of selection and extraction of diamonds from a mixture of accompanying minerals grains, based on their different ability to transmit heat flow, is highly selective. In this case, thermal contact of diamonds with substances that have high thermo-adhesive properties should be used for the extraction of diamonds. When such substances come into contact with diamond, selectively high heat flows provide a rapid melting of the working material, followed by curing and fixing the diamond grains. Further, it is possible and expedient to use the mechanical separation of diamond grains from a thermo-adhesion substance with the collection of finished diamond raw materials.

The purpose of this work is to evaluate the heat transfer in the thermo-adhesion method of extracting diamond raw materials from a mixture of accompanying minerals. 


\section{Heat Transfer Scheme and Estimated Calculations to Justify the Thermo-Adhesion Method}

Heat transfer is a key issue of the proposed method of extraction of raw diamond grains. In the work, estimated calculations of heat flows for particle separation were carried out, based on the thermal physical properties of diamond and related minerals, the geometric data of the technological scheme.

For comparison, Table 1 shows the thermal conductivity of diamond, metals, kimberlite, sedimentary rocks and minerals (Wei et al., 1993; Shvartsman, 2007; Dortman, 1984; Bukhmirov, Rakutina, \& Solnyshkova, 2009). As it is seen from the table, the coefficient of thermal conductivity of a diamond is $\sim 10^{2}-10^{3}$ higher than the coefficients of thermal conductivity of kimberlite, other minerals and sedimentary rocks of a kimberlite pipe. As noted above, this provides a high selectivity of thermo-adhesion extraction of diamond grains.

In the work for estimated calculations, heat transfer in the "heating element - diamond (mineral) - thermo-adhesion substance" scheme is considered (Figure 1). The temperatures of the heating element and the thermo-adhesion substance $\mathrm{T} 2$ and $\mathrm{T} 1$, respectively, are assumed to be constant, this is possible by adjustment in technological devices. Then, as it seen from the scheme, the main characteristic of heat transfer is the thermal conductivity of diamond grains or an related mineral.

In the estimated calculations, we can use the formula for heat passing through a diamond, obtained from the Fourier law (Bukhmirov, Rakutina, \& Solnyshkova, 2009; Sedov, 1987):

$$
Q=\frac{\lambda S t d T}{l} f\left(\frac{r}{R}\right)
$$

where $Q$ - the amount of transferred heat, $\mathrm{J} ; S$ - the cross-section of the particle contact, $\mathrm{m}^{2} ; t-$ duration of heat transfer, sec; $d T$ - the temperature difference $d T=T 2-T 1, \mathrm{~K} ; l$ - longitudinal grain size, $\mathrm{m} ; \lambda$ - the coefficient of thermal conductivity of the material, $\mathrm{W} /(\mathrm{m} \cdot \mathrm{K})$.

Table 1. Coefficients of thermal conductivity of various materials (Wei et al., 1993; Shvartsman, 2007; Dortman, 1984; Bukhmirov, Rakutina, \& Solnyshkova, 2009)

\begin{tabular}{llll}
\hline Material & Thermal conductivity, W/(m/K) & Material & Thermal conductivity, W/(m/K) \\
\hline Diamond & $1001-2300$ & Kimberlite & 2.1 \\
Silver & 430 & Sedimentary rocks of kimberlite pipe & $2.3-2.5$ \\
Copper & 401 & Quatrz & 8.0 \\
Gold & 320 & Granite & 2.4 \\
Iron & 92 & Basalt & 1.3 \\
Steel & 47 & Olivin & 5.07 \\
Tin & 54 & Feldspar & 0.71 \\
\hline
\end{tabular}

The function $0 \leq f(r / R) \leq 1$ is introduced as a characteristic of the particle shape and takes into account the spreading of the heat flow passing through the contact ( $\mathrm{r}, \mathrm{R}$ - the characteristic dimensions of the contact and the cross section of the particle). The estimated calculations were carried out under the assumption $f(r / R) \rightarrow 1$ and the isometry of the grains $R \approx l$ for simplicity.

The proposed scheme for extraction of diamond grains involves the movement of a layer of a thermo-adhesion substance on a conveyor belt. Then the main technological characteristics can be estimated by the following formulas (2)-(3). The speed of the belt with a thermo-adhesion substance:

$$
V=\frac{l}{t},
$$

mass of molten thermo-adhesion substance:

$$
m=\frac{Q}{k},
$$

where $k$ - the specific melting heat of the thermo-adhesion substance.

Figure 2 shows the results of calculation of the amount of heat for diamond raw materials. As might be expected, the heat flow increases linearly with increasing temperature difference, as well as with increasing thermal conductivity of the diamond particle (Figure 2,a). The amount of heat passing through the diamond, depending on the particle size, decreases according to the hyperbolic dependence (Figure 2,b). The surface graph of heat flow can be used for clarity (Figure 3). 
In Figure 3 the results of calculating the amount of heat for diamond grains are shown. As follows from formula (1), the heat flow increases linearly with increasing temperature difference, as well as with increasing thermal conductivity of the diamond particle. The amount of heat passing through the diamond decreases in inverse relationship to the grain size (Figure 3).

As it is seen from formula (1), the amount of heat passing through the diamond particle is $\sim 2-3$ orders of magnitude higher than amount of heat passing through the related mineral of the kimberlite rock; this justifies the proposed scheme for the selection of diamond raw materials. The high thermal conductivity of a diamond is due to the rapid selective melting of the thermo-adhesion substance layer during the motion of the belt (Figure 1).

In Figure 4.5 the results of calculating the amount of heat for the related minerals are shown. The amount of heat also increases linearly with increasing temperature difference, and with increasing thermal conductivity of the particle (Figure 4,a).

Comparison of the graphs in Figure 3 and Figure 5 shows, that the amount of heat passing through the diamond particle is three orders of magnitude higher than amount of heat passing through the mineral particle, which theoretically justifies the proposed scheme for the selection of diamond raw materials. The very high thermal conductivity of a diamond causes a high heat transfer, which necessary for melting the thermo-adhesion substance (Figure 1).

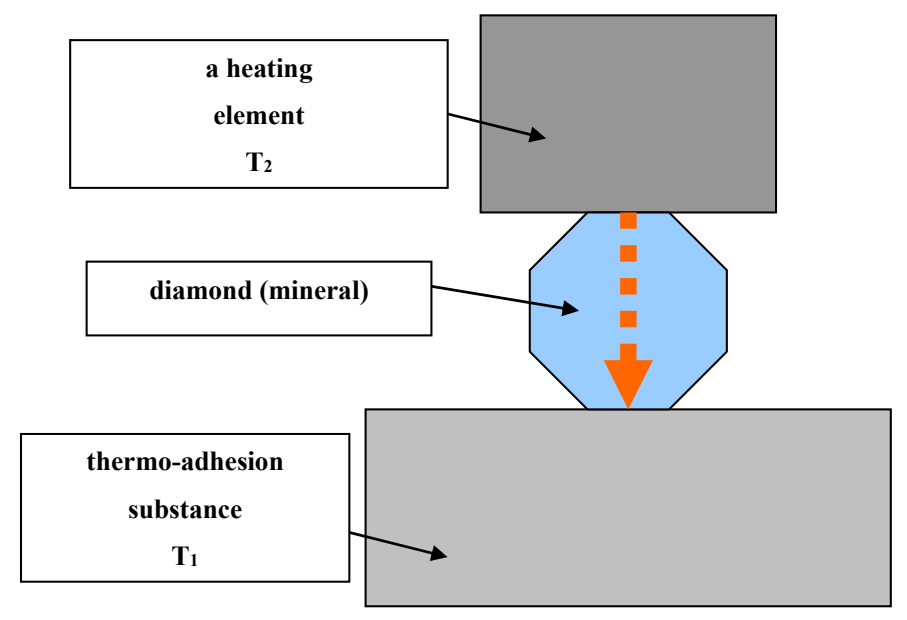

Figure 1. Heat transfer scheme of thermo-adhesion method

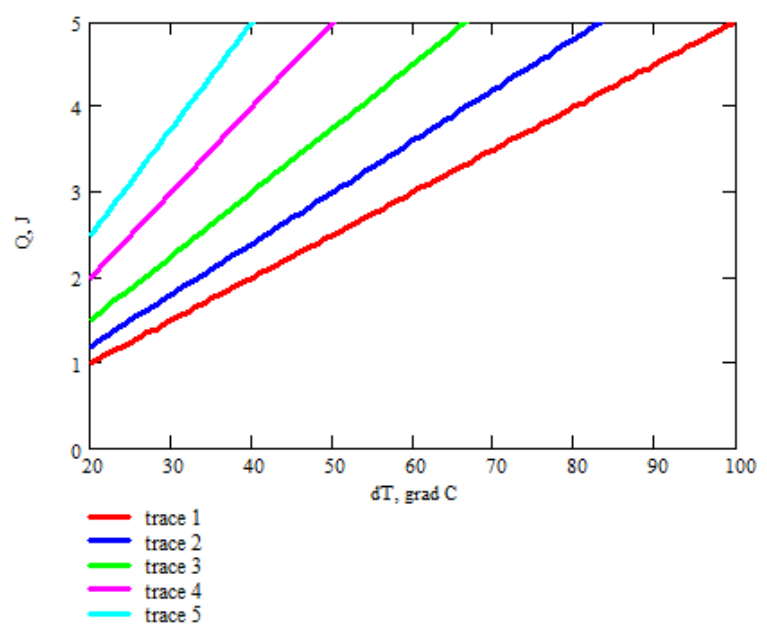

a

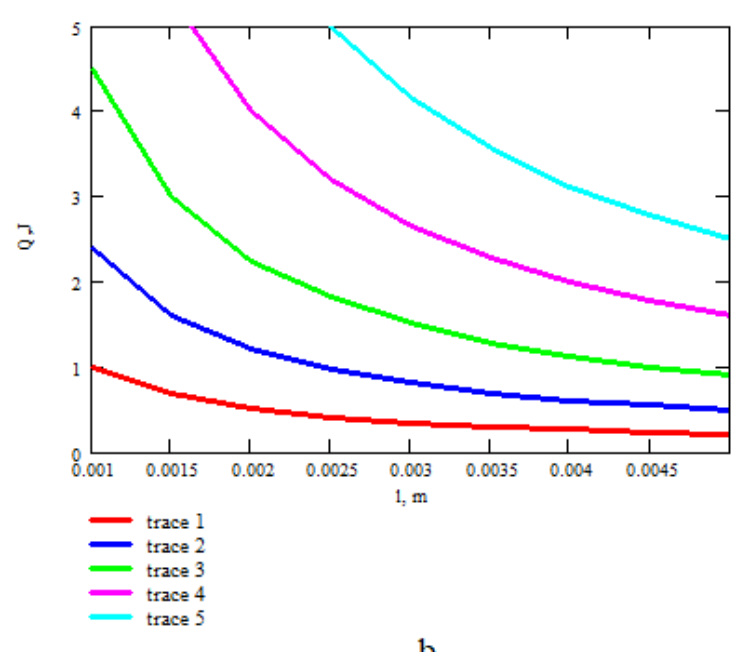

b

Figure 2. Calculation of the amount of heat for diamond raw materials: a) dependence on the temperature difference, 1- $20{ }^{\circ} \mathrm{C}, 2-40{ }^{\circ} \mathrm{C}, 3-60{ }^{\circ} \mathrm{C}, 4-80^{\circ} \mathrm{C}, 5-100{ }^{\circ} \mathrm{C}$; b) the dependence on the grain size, $1-1000 \mathrm{~W} /(\mathrm{m} \cdot \mathrm{K}), 2-1200$ $\mathrm{W} /(\mathrm{m} \cdot \mathrm{K}), 3-1500 \mathrm{~W} /(\mathrm{m} \cdot \mathrm{K}), 4-2000 \mathrm{~W} /(\mathrm{m} \cdot \mathrm{K}), 5-2500 \mathrm{~W} /(\mathrm{m} \cdot \mathrm{K})$ 


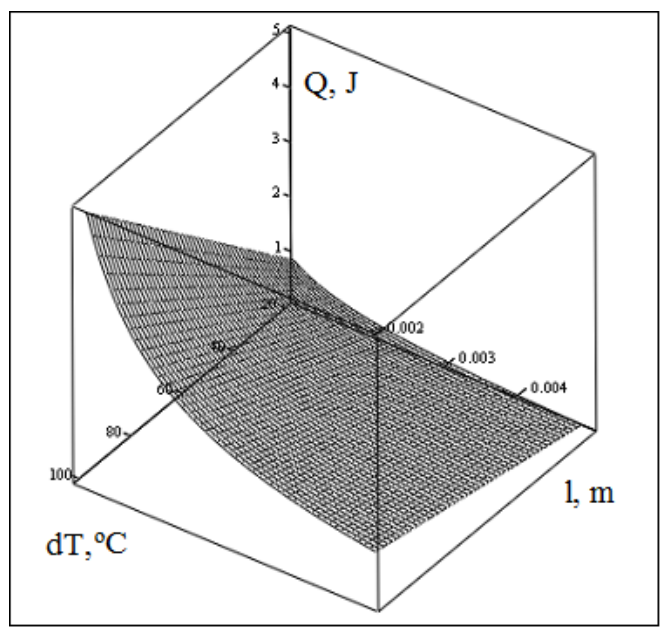

Figure 3. Calculation of the heat flow in diamond; $\lambda=1000 \mathrm{~W} /(\mathrm{m} \cdot \mathrm{K}), \mathrm{t}=0,05 \mathrm{sec}, \mathrm{S}=1 \mathrm{~mm}^{2}$
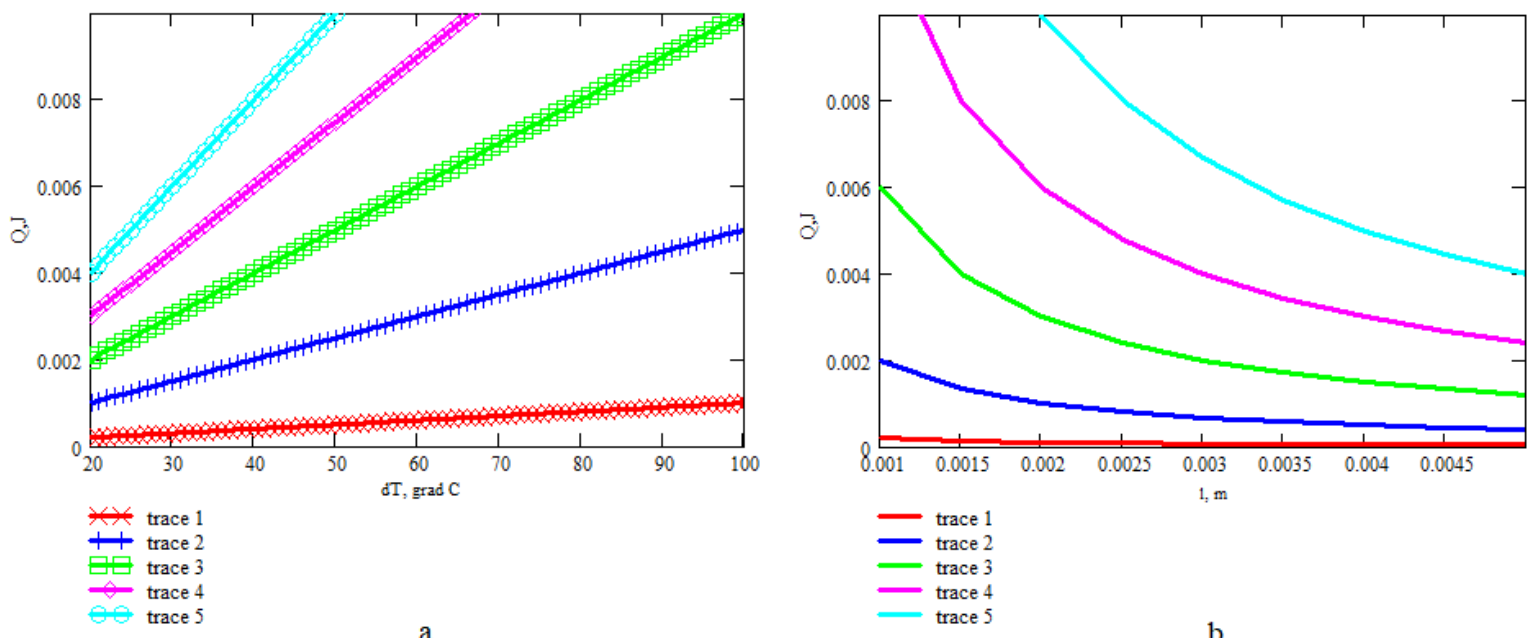

Figure 4. Calculation of the amount of heat for the accompanying minerals: a) dependence on the temperature difference, $1-20^{\circ} \mathrm{C}, 2-40{ }^{\circ} \mathrm{C}, 3-60^{\circ} \mathrm{C}, 4-80^{\circ} \mathrm{C}, 5-100^{\circ} \mathrm{C}$; b) dependence on grain size, $1-0,1 \mathrm{~W} /(\mathrm{m} \cdot \mathrm{K}), 2-0,5$ $\mathrm{W} /(\mathrm{m} \cdot \mathrm{K}), 3-1 \mathrm{~W} /(\mathrm{m} \cdot \mathrm{K}), 4-1,5 \mathrm{~W} /(\mathrm{m} \cdot \mathrm{K}), 5-2 \mathrm{~W} /(\mathrm{m} \cdot \mathrm{K})$

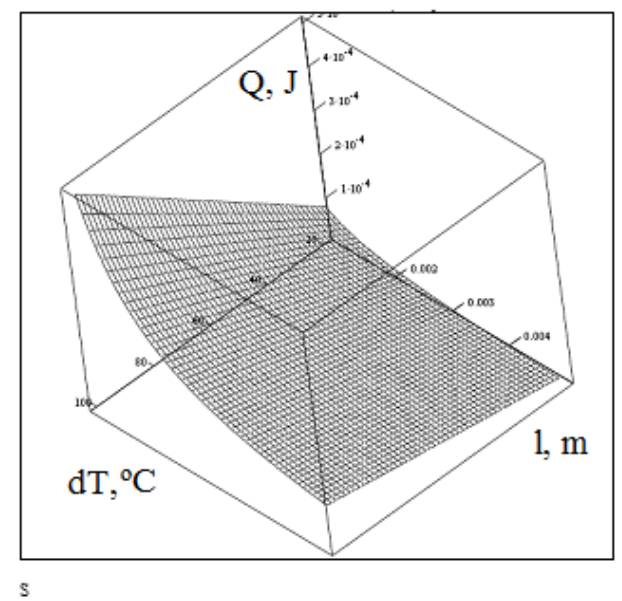

Figure 5. Calculation of the amount of heat for the accompanying minerals; $1=1 \mathrm{~mm} ; \mathrm{t}=0,05 \mathrm{sec}, \mathrm{S}=1 \mathrm{~mm}^{2}$ 


\section{Experimental Study of Heat Transfer Processes for the Thermo-Adhesion Method}

In this work, experimental studies of heat exchange processes were conducted to confirm the theoretical justification of the thermo-adhesion method.

The technological parameters of the proposed thermo-adhesion method for selection, and extraction of diamond from a mixture of related mineral grains are specified based on the results of the experiments. It is possible to transform formula (2) for the speed of the conveyor belt $V$ as a function of the temperature of the roller-heater $T$ from the theory of heat transfer (Sedov, 1987) using experimental data and similarity relationships:

$$
V(T)=\frac{l_{\ni}\left(T-T_{\Pi Л}\right)}{t_{\ni}\left(T_{2}-T_{\Pi Л}\right)},
$$

where the following experimental data were used - the size of the diamond grain $l_{5}$, the time required for melting the thermo-adhesive layer $t_{3}$, the melting temperature of the thermo-adhesion substance of $T_{\text {Плл }}$ the maximum temperature of the roller heater $T_{2}$.

Figure 6 shows the linear dependence (4) of the conveyor belt speed with the thermo-adhesion substance on the temperature of the heater $\mathrm{T}$. The experimental data obtained by the test thermo-adhesion extraction unit are indicated by the markers on the graph. As it is seen from the graph, when the roller temperature of the heater is raised to $350{ }^{\circ} \mathrm{C}$, the speed of the belt necessary for melting the thermo-adhesion substance can be increased to $\approx 100$ $\mathrm{mm} / \mathrm{s}$. Also, it is established that the results of the estimated calculations are in satisfactory agreement with the control experimental data in comparison (Figure 6).

The most important property of a thermo-adhesion substance is its sufficient strength of contact with the diamond, in addition to its melting temperature, to the efficiency of the developed method for selecting and extracting diamonds from a mixture of accompanying minerals grains. This ensures the reliability of securing the diamond grains in the conveyor belt chutes; before-time loss of precious grains should be ruled out.

Therefore, in work the adhesion strength of contacts "diamond-pure rosin" and "diamond-compositions on the basis of rosin" were tested. A sample of natural diamond, one surface of which was polished on a lapping machine, was used for measurements. Adhesion strength tests were carried out by the normal tear-off method after curing the thermo-adhesion layer on the diamond surface at room temperature.

The results of the conducted strength contacts studies are given in Table 2. As it is seen from the table, in spite of the fact that paraffin adheres to diamond at a temperature on $13{ }^{\circ} \mathrm{C}$ lower than that of rosin, its adhesion strength to the smooth surface of diamond is about $\approx 2$ times lower than that of rosin. Compositions of rosin with beeswax and paraffin also have a lower adherence temperature to the diamond, but the adhesion strength to diamond is several tens of percent lower than that of pure rosin.

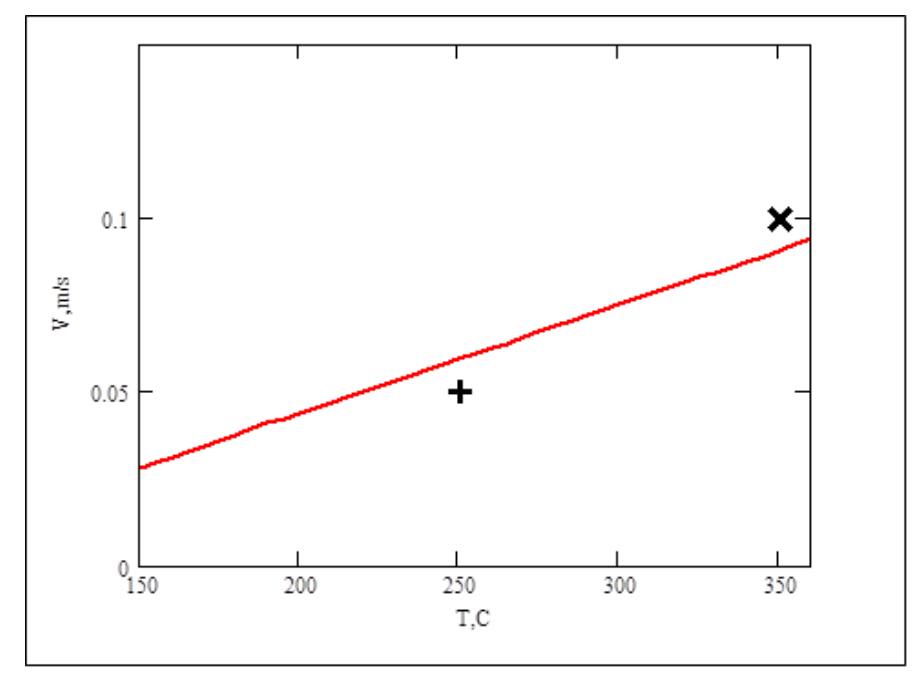

Figure 6. Dependence of the belt speed with the thermo-adhesion layer on the temperature of the roller-heater $T$ : line - calculation, markers - experiment 
Table 2. Strength of contacts "diamond-thermo-adhesion substance"

\begin{tabular}{|c|c|c|c|c|}
\hline \multirow{2}{*}{ № } & \multirow{2}{*}{ Thermo-adhesion substance } & \multirow{2}{*}{$\begin{array}{l}\text { Melting temperature and } \\
\text { adherence temperature to } \\
\text { diamond, }{ }^{\circ} \mathrm{C}\end{array}$} & \multicolumn{2}{|c|}{ Strength of contact } \\
\hline & & & $\mathrm{kgf} / \mathrm{mm}^{2}$ & $\mathrm{MPa}$ \\
\hline 1 & Rosin (pine), $100 \%$ & $68 \pm 5$ & 1.29 & 12.65 \\
\hline 2 & Rosin+beeswax $(50 \%+50 \%)$ & $64 \pm 5$ & 0.732 & 7.18 \\
\hline 3 & Rosin + paraffine $(50 \%+50 \%)$ & $60 \pm 4$ & 0.701 & 6.87 \\
\hline 4 & Paraffin, $100 \%$ & $55 \pm 5$ & 0.830 & 6.26 \\
\hline
\end{tabular}

Thus, the prospects and high efficiency of the thermo-adhesion method of selection and extraction of diamonds are justified theoretically and experimentally.

\section{Conclusion}

1) Thermo-adhesion method of selection and extraction of diamond grains according to thermal physical properties from a mixture of related minerals is justified and proposed. The method is intended to improve the efficiency of sorting diamonds in the final refinement of the enriched concentrate of kimberlite ore that has undergone X-ray luminescence separation.

2) Heat transfer estimated calculations show that due to a very large difference in the thermal conductivity of diamond and related minerals, a high selectivity of the thermo-adhesion and diamond recovery process is provided, with separation of the concentrate into a useful component and an empty rock.

3) Investigations of the strength of contacts of thermo-adhesion substances with diamond - "diamond-pure rosin" and "diamond-compositions on the basis of rosin". It is established that for the developed method of selection and extraction of diamond grains as a thermo-adhesion substance, it is preferable to use pure rosin.

\section{References}

Banas, A., Stachel, T., Muehlenbachs, K., \& McCandless, T. E. (2007). Diamonds from the Buffalo Head Hills, Alberta: Formation in a non-conventional setting. Lithos, 93(1), 199-213.

Bukhmirov, V. V., Rakutina, D. V., \& Solnyshkova, Iu. S. (2009). Spravochnye materialy dlia re-sheniia zadach po kur-su «Teplomassoobmen». - Ivanovo.: GOU VPO «Ivanovskii gosu-darstvennyi energeticheskii universitet imeni V.I. Lenina», - 2009. - 102 s.

Chaikovskii, I. I., Korotchenkova, O. V., Teterin, I. P., Morozov, G. G., \& Kirillov, V. A. (2013). Novyi tip almaznykh mestorozhdenii - visherskii. Gornyi zhurnal, 6, S.12-16.

Chanturiia, V. A., Chaadaev, A. S., Dvoichenkova, G. P., Ostrovskaia, G. Kh., \& Trofimova, E. A. (2012). Emul'sionnyi metod ochistki almazosoderzhashchikh kontsentratov lipkostnoi $\mathrm{i}$ pen-noi separatsii ot organicheskikh primesei. Gornyi zhurnal, 12, S.79-83.

Dement'ev, V. E., Voiloshnikov, G. I., \& Kononko, R. V. (2015). Sovershenstvovanie sposobov iz-vlecheniia dragotsen-nykh metallov i almazov iz mineral'nogo syr'ia. Gornyi zhurnal, 9, S.28-32.

Dortman, N. B. (1984). Fizicheskie svoistva gornykh porod i poleznykh iskopaemykh. Nedra.

Fedorov, I. I., Chepurov, A. A., \& Dereppe, J. M. (2002). Redox conditions of metal-carbon melts and natural diamond genesis. Geochemical Journal, 36, 247-253.

Howell, D. (2012). Strain-induced birefringence in natural diamond: a review. European Journal of Mineralogy, 24(4), 575-585.

Makarskii, I. V. (2012). Kontrol' kachestva ochistki almazov s pomoshch'iu spektrofotometra Lambda 950». Gornyi zhurnal, 12, S.74-77.

Maréchal, A., Rouger, N., Crebier, J. C., Pernot, J., Koizumi, S., Teraji, T., \& Gheeraert, E. (2014). Model implementation towards the prediction of $\mathrm{J}(\mathrm{V})$ characteristics in diamond bipolar device simulations. Diamond and Related Materials, 43, 34-42.

Milashev, V. A. (2013). Almazy rossiiskogo zapoliar'ia. Gornyi zhurnal, 11, S.47-51.

Monticone, D. G., Quercioli, F., Mercatelli, R., Soria, S., Borini, S., Poli, T., ... \& Olivero, P. (2013). Systematic study of defect-related quenching of NV luminescence in diamond with time-correlated single-photon counting spectroscopy. Physical Review B, 88(15), 155-201. 
Mukhin, P. A, Riu, G., \& Francheskini, D. (2015). Poiski, razvedka i dobycha almazov v pribrezh-noi zone shel'fa tsent-ral'noi chasti Namibii. Gornyi zhurnal, 1, S.85-97.

Pastewka, L., Moser, S., Gumbsch, P., \& Moseler, M. (2011). Anisotropic mechanical amorphization drives wear in diamond. Nature materials, 10(1), 34-38. https://doi.org/10.1038/nmat2902

Sedov, L. I. (1987). Metody podobiia i razmernosti v mekhanike. Nauka.

Shirey, S. B., Harris, J. W., Richardson, S. H., Fouch, M. J., James, D. E., Cartigny, P., ... \& Viljoen, F. (2002). Diamond genesis, seismic structure, and evolution of the Kaapvaal-Zimbabwe craton. Science, 297(5587), 1683-1686.

Shvartsman, Iu. G. (2007). Teplovoe sostoianie litosfery zimneberezhnogo almazonosnogo raiona. / Materialy Vse-rossiiskoi konferentsii «Geodinamika, magnetizm, sedi-mentogenez i minerageniia Severa-zapada Rossii». Petrozavodsk, 12-15 noiab-ria, S.436-439.

Tappert, R., \& Tappert, M. C. (2011). Diamonds in nature: a guide to rough diamonds. Springer Science \& Business Media.

Wei, L., Kuo, P. K., Thomas, R. L., Anthony, T. R., \& Banholzer, W. F. (1993). Thermal conductivity of isotopically modified single crystal diamond. Physical Review Letters, 70(24), 3764.

\section{Copyrights}

Copyright for this article is retained by the author(s), with first publication rights granted to the journal.

This is an open-access article distributed under the terms and conditions of the Creative Commons Attribution license (http://creativecommons.org/licenses/by/4.0/). 